\title{
Etiology of IgG4-Related Pulmonary Hypertension
}

\author{
Mitsuhiro Akiyama Yuko Kaneko Tsutomu Takeuchi \\ Division of Rheumatology, Department of Internal Medicine, Keio University School of \\ Medicine, Tokyo, Japan
}

\section{Dear Editor,}

IgG4-related disease (IgG4-RD) affects every single organ of the body [1-6], but little is known about pulmonary hypertension associated with IgG4-RD. Appropriate treatment is generally crucial for the prevention of irreversible organ damage in IgG4-RD [7-10], but especially with pulmonary hypertension because it is frequently serious and fatal.

We conducted a literature review of IgG4-related pulmonary hypertension and identified a total of 7 patients [1, 11-15], who satisfied the IgG4-RD comprehensive diagnostic criteria [16] (Fig. 1a). Their age ranged from 22 to 69 years. Four were male and 3 were female. All patients presented with dyspnea. Pulmonary hypertension was assessed by right heart catheterization in 5 patients and by echocardiography in 2 patients (Fig. 1a). Remarkably, those cases could be classified into two types based on imaging possibly related to causal etiology: (i) "IgG4-related fibrosing mediastinitis type" or (ii) "IgG4-related lung disease type" as shown in Figure 1a.

IgG4-related fibrosing mediastinitis lesion was determined by tumefactive mediastinal lesions in the images. All 5 patients with IgG4-related fibrosing mediastinitis showed no evidence of IgG4-related lung disease lesions (Fig. 1a). On the other hand, the 2 patients with IgG4-related lung dis- ease did not show any evidence of IgG4related mediastinitis lesions as well as pulmonary large-vessel compression in the images (Fig. 1a). This suggests that there are 2 different etiologies of IgG4-related pulmonary hypertension (Fig. 1b). In the IgG4-related fibrosing mediastinitis type, the proximal medium-to-large-sized pulmonary artery was mechanically compressed from the outside by tumefactive mass lesions within the mediastinal space. In the IgG4-related lung disease type, the intense lymphoplasmacytic infiltration secondary to obliterative phlebitis or obliterative arteritis in the lungs occupied distal pulmonary microvessels as a causal etiology of pulmonary hypertension [1].

While IgG4-related fibrosing mediastinitis has recently been proposed as a possible etiology of idiopathic fibrosing mediastinitis [5], fibrosing mediastinitis itself is classically known as a cause of pulmonary hypertension by compressing the mediumto-large-sized proximal pulmonary artery [17]. IgG4-related fibrosing mediastinitis shows elevated levels of serum C-reactive protein without multi-organ involvement [4], in line with the cases with pulmonary hypertension of "IgG4-related fibrosing mediastinitis type" (Fig. 1a). On the other hand, IgG4-related lung disease causes obliterative vasculitis of microvessels, which can lead to pulmonary hypertension. A study examined the tissue sections from patients with IgG4-related lung disease and revealed the frequent presence of obliterative vasculitis lesions in the lungs [18].

IgG4-related lung disease frequently presents with multiple organ involvements and normal serum C-reactive protein, which is consistent with the IgG4-related lung disease type in our present study (Fig. 1a). Moreover, we need to note that there is the possibility of another etiology of pulmonary hypertension which has yet to be reported; pulmonary vasculitis due to IgG4-RD. Pulmonary vasculitis has been reported to cause pulmonary hypertension in other vasculitic diseases $[19,20]$, and IgG4-RD causes systemic vasculitis [6]. The reason for no previous reports with this etiology might be the difficulty in obtaining specimens of pulmonary vessels for histopathological confirmation.

Glucocorticoid treatment is usually effective for patients with IgG4-RD [2]. Importantly, all 7 patients with IgG4-related pulmonary hypertension responded well to immunosuppressive treatments including glucocorticoid without pulmonary vasodilators such as prostacyclin analogues, endothelin receptor antagonists, and phosphodiesterase- 5 inhibitors (Fig. 1a). Therefore, we need to be attentive to clinical

\footnotetext{
karger@karger.com

(c) 2020 S. Karger AG, Basel

www.karger.com/crd
}

Karger"
Dr. Yuko Kaneko

Division of Rheumatology, Department of Internal Medicine

Keio University School of Medicine

35 Shinanomachi, Shinjuku-ku, Tokyo (Japan)

ykaneko.z6@keio.jp 


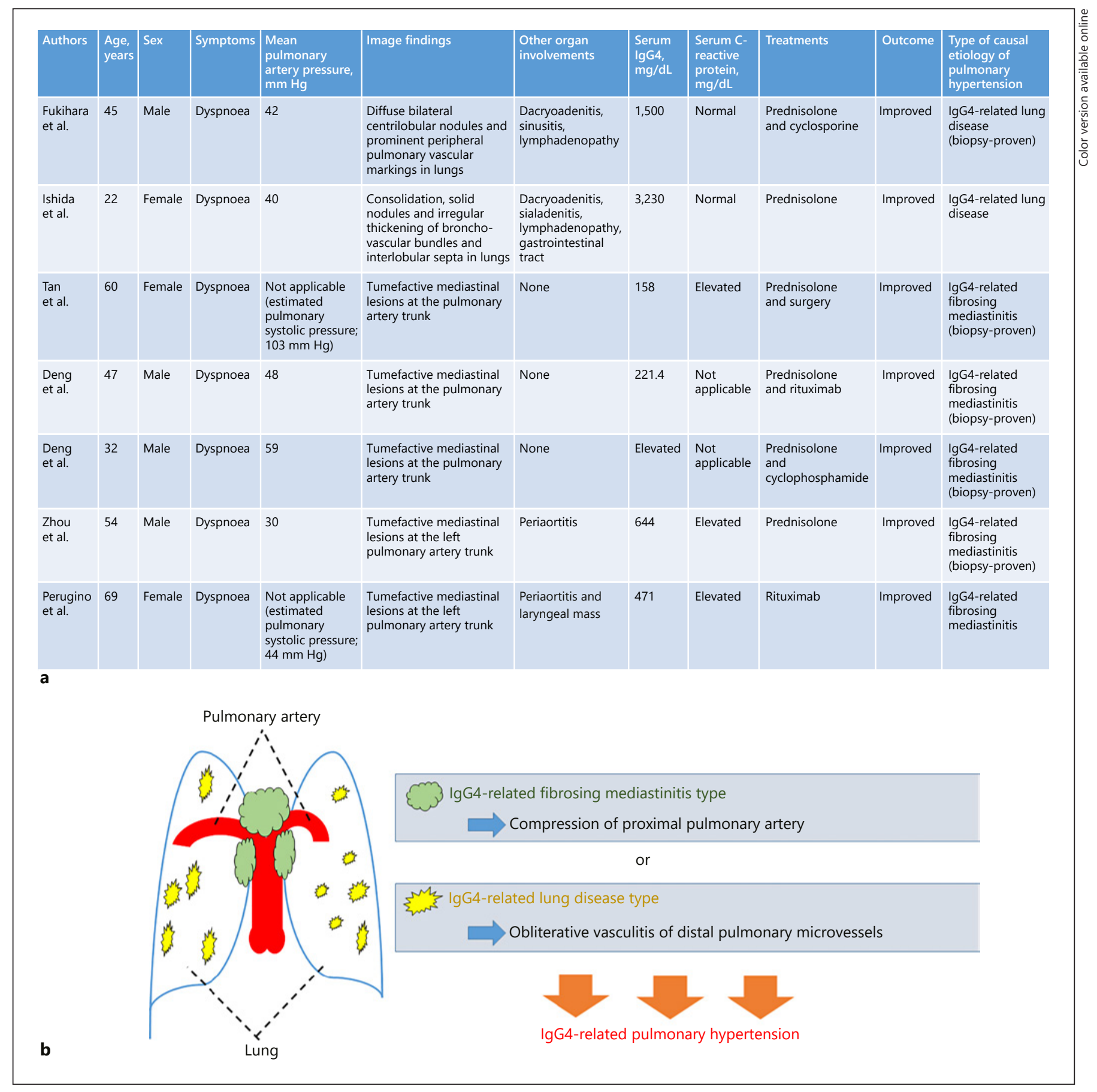

Fig. 1. a. Summary of the reported cases of IgG4-related pulmonary hypertension. b. Model for the two possible etiologies of IgG4-related pulmonary hypertension.

manifestations of IgG4-related pulmonary hypertension to avoid a delay in diagnosis and immunosuppressive treatment initiation for this serious but treatable organ involvement. Echocardiography, right heart catheterization, and biopsy should be con- sidered in cases of unexplained dyspnea complicated with IgG4-related mediastinitis or lung disease.

IgG4-RD frequently relapses during glucocorticoid tapering [21], and longterm outcome remains unclear particularly in IgG4-related pulmonary hypertension. Further accumulations of cases and longitudinal studies are needed for a better understanding of the disease and for establishing treatment strategies for patients with IgG4-related pulmonary hypertension. 


\section{Disclosure Statement}

M.A. reports no conflicts of interest related to this article. Y.K. has received grants or speaker fees from AbbVie, Astellas, Ayumi, Bristol-Myers Squibb, Chugai, Eisai, Eli Lilly, Hisamitsu, Jansen, Kissei, Pfizer, Sanofi, Takeda, Tanabe-Mitsubishi, and UCB. T.T. has received research grants or speaking fees from Astellas Pharma Inc.,

\section{References}

1 Fukihara J, Kondoh Y, Taniguchi H, Kimura T, Kataoka K, Matsuda T, et al. Pulmonary hypertension associated with obliterative phlebitis in IgG4-related lung disease. Eur Respir J. 2015 Mar;45(3):842-5.

2 Akiyama M, Takeuchi T. IgG4-Related Disease: beyond Glucocorticoids. Drugs Aging. 2018 Apr;35(4):275-87.

3 Akiyama M, Suzuki K, Yasuoka H, Kaneko Y, Yamaoka K, Takeuchi T. Follicular helper T cells in the pathogenesis of IgG4-related disease. Rheumatology (Oxford). 2018 Feb; 57(2):236-45.

4 Akiyama M, Yasuoka H, Yoshimoto K, Takeuchi T. CC-chemokine ligand 18 is a useful biomarker associated with disease activity in IgG4-related disease. Ann Rheum Dis. 2018 Sep;77(9):1386-7

5 Takanashi S, Akiyama M, Suzuki K, Otomo K, Takeuchi T. IgG4-related fibrosing mediastinitis diagnosed with computed tomographyguided percutaneous needle biopsy: two case reports and a review of the literature. Medicine (Baltimore). 2018 Jun;97(22):e10935.

6 Akiyama M, Kaneko Y, Takeuchi T. Characteristics and prognosis of IgG4-related periaortitis/periarteritis: A systematic literature review. Autoimmun Rev. 2019 Sep;18(9): 102354.

7 Anan R, Akiyama M, Kaneko Y, Kikuchi J, Suzuki K, Matsubara S, et al. Polymyositis with elevated serum IgG4 levels and abundant IgG4+ plasma cell infiltration: A case report
Bristol-Myers K.K., Chugai Pharmaceutical Co, Ltd, Daiichi Sankyo Co., Ltd, Takeda Pharmaceutical Co., Ltd, Teijin Pharma Ltd, AbbVie GK, Asahi Kasei Pharma Corp., Mitsubishi Tanabe Pharma, Astra Zeneca K.K., Eli Lilly Japan K.K., Novartis Pharma K.K., AbbVie GK, Nippon Kayaku Co. Ltd, Janssen Pharmaceutical K.K., Taiho Pharmaceutical Co., Ltd., and Pfizer Japan Inc.

and literature review. Medicine (Baltimore). 2017 Dec;96(48):e8710.

8 Sasaki T, Akiyama M, Kaneko Y, Mori T, Yasuoka $\mathrm{H}$, Suzuki K, et al. Distinct features distinguishing IgG4-related disease from multicentric Castleman's disease. RMD Open. 2017 Jul;3(1):e000432.

9 Akiyama M, Kaneko Y, Hayashi Y, Takeuchi T. IgG4-related disease involving vital organs diagnosed with lip biopsy: A case report and literature review. Medicine (Baltimore). 2016 Jun;95(24):e3970.

10 Akiyama M, Yasuoka H, Yamaoka K, Suzuki $\mathrm{K}$, Kaneko Y, Kondo H, et al. Enhanced IgG4 production by follicular helper $2 \mathrm{~T}$ cells and the involvement of follicular helper $1 \mathrm{~T}$ cells in the pathogenesis of IgG4-related disease. Arthritis Res Ther. 2016 Jul;18(1):167.

11 Zhou Y, Shao L, Ruan W, Jin J, Xu H, Ying K, et al. Pulmonary vascular involvement of IgG4-related disease: case series with a PRISMA-compliant systemic review. Medicine (Baltimore). 2019 Feb;98(6):e14437.

12 Deng H, Zhao S, Yue Y, Liu Y, Xu Y, Qian J, et al. IgG4-related disease of pulmonary artery causing pulmonary hypertension. Medicine (Baltimore). 2018 May;97(20):e10698.

13 Perugino CA, Wallace ZS, Meyersohn N, Oliveira G, Stone JR, Stone JH. Large vessel involvement by IgG4-related disease. Medicine (Baltimore). 2016 Jul;95(28):e3344.

14 Tan M, Li Z, Tang H, Sun G, Xu Z. IgG4-Related Tumefactive Lesions at the Pulmonary

\section{Funding Sources}

This research did not receive any specific grant from funding agencies in the public, commercial, or non-profit sectors.

\section{Author Contributions}

All authors contributed to the writing of the manuscript and discussion of the results.

Artery Causing Stenosis of Bilateral Primary Branches and Resultant Pulmonary Hypertension. Cardiology. 2019;143(3-4):136-44.

15 Ishida M, Miyamura T, Sato S, Kimura D, Suematsu E. Pulmonary arterial hypertension associated with IgG4-related disease. Intern Med. 2014;53(5):493-7.

16 Umehara H, Okazaki K, Masaki Y, Kawano M, Yamamoto M, Saeki T, et al. Comprehensive diagnostic criteria for IgG4-related disease (IgG4-RD), 2011. Mod Rheumatol. 2012 Feb;22(1):21-30.

17 Sherrick AD, Brown LR, Harms GF, Myers JL. The radiographic findings of fibrosing mediastinitis. Chest. 1994 Aug;106(2):484-9.

18 Zen Y, Inoue D, Kitao A, Onodera M, Abo H, Miyayama S, et al. IgG4-related lung and pleural disease: a clinicopathologic study of 21 cases. Am J Surg Pathol. 2009 Dec;33(12): 1886-93.

19 Wang X, Dang A, Chen B, Lv N, Liu Q. Takayasu arteritis-associated pulmonary hypertension. J Rheumatol. 2015 Mar;42(3): 495-503.

20 Rubin LA, Geran A, Rose TH, Cohen H. A fatal pulmonary complication of lupus in pregnancy. Arthritis Rheum. 1995 May;38(5): 710-4.

21 Sasaki T, Akiyama M, Kaneko Y, Yasuoka H, Suzuki K, Yamaoka K, et al. Risk factors of relapse following glucocorticoid tapering in IgG4-related disease. Clin Exp Rheumatol. 2018 May-Jun;36 Suppl 112(3):186-189. 